\title{
Review \\ Update on Biomarkers Associated to Cardioembolic Stroke: A Narrative Review
}

\author{
Ana Catarina Fonseca ${ }^{1,2,3, *(D)}$ and Pedro Coelho ${ }^{1}$ (D) \\ 1 Department of Neurology, Hospital de Santa Maria, 1640-035 Lisboa, Portugal; peminco@gmail.com \\ 2 Institute of Molecular Medicine, 1649-028 Lisboa, Portugal \\ 3 Faculdade de Medicina, Universidade de Lisboa, 1649-028 Lisboa, Portugal \\ * Correspondence: acfonseca@medicina.ulisboa.pt
}

Citation: Fonseca, A.C.; Coelho, P.

Update on Biomarkers Associated to Cardioembolic Stroke: A Narrative Review. Life 2021, 11, 448. https:// doi.org/10.3390/life11050448

Academic Editors: Pedro Castro,

Elsa Azevedo and Alexey

V. Polonikov

Received: 6 April 2021

Accepted: 15 May 2021

Published: 17 May 2021

Publisher's Note: MDPI stays neutral with regard to jurisdictional claims in published maps and institutional affiliations.

Copyright: (c) 2021 by the authors. Licensee MDPI, Basel, Switzerland. This article is an open access article distributed under the terms and conditions of the Creative Commons Attribution (CC BY) license (https:// creativecommons.org/licenses/by/ $4.0 /)$.

\begin{abstract}
Background: In the last years, several studies were conducted that evaluated biomarkers that could be helpful for cardioembolic stroke diagnosis, prognosis, and the determination of risk of stroke recurrence. Methods: We performed a narrative review of the main studies that evaluated biomarkers related to specific cardioembolic causes: atrial fibrillation, patent foramen ovale, atrial cardiomyopathy, and left ventricular wall motion abnormalities. Results: BNP and NT-proBNP are, among all biomarkers of cardioembolic stroke, the ones that have the highest amount of evidence for their use. NT-proBNP is currently used for the selection of patients that will be included in clinical trials that aim to evaluate the use of anticoagulation in patients suspected of having a cardioembolic stroke and for the selection of patients to undergo cardiac monitoring. NT-proBNP has also been incorporated in tools used to predict the risk of stroke recurrence (ABC-stroke score). Conclusions: NT-proBNP and BNP continue to be the biomarkers most widely studied in the context of cardioembolic stroke. The possibility of using other biomarkers in clinical practice is still distant, mainly because of the low methodological quality of the studies in which they were evaluated. Both internal and external validation studies are rarely performed for most biomarkers.
\end{abstract}

Keywords: biomarker; cardioembolism; stroke; atrial fibrillation; patent foramen ovale; atrial cardiomyopathy; NT-proBNP; BNP; ANP

\section{Introduction}

In many areas of medicine, biomarkers are currently used to help to diagnose, establish prognoses, and to prescribe therapeutics to specific groups of patients that benefit the most from differentiated treatments due to having particular phenotypes [1]. Moreover, in neurology, several studies that evaluated biomarkers have been conducted in recent years, namely in the area of stroke [2]. When compared to other medical areas, the application of biomarkers to the field of cerebrovascular pathology has some obstacles: (a) the presence of the blood-brain barrier that poses difficulties and delays the release of proteins of neuronal or glial origin into the bloodstream after stroke; and (b) many of the potential serum biomarkers of cerebral ischemia and inflammation have low specificity and may also be increased in situations that can be confounded with stroke as they may present in a similar way such as acute myocardial infarction or central nervous system inflammation [3].

Nevertheless, there could be clear benefits of the application of biomarkers in stroke. Unravelling the cause of ischemic stroke can sometimes be challenging [4]. After an extensive investigation about a third of ischemic stroke patients are classified as having an undetermined stroke etiology [4]. It is possible that a fraction of these strokes that are currently being classified as of undetermined etiology may indeed be cardioembolic. Cardioembolic strokes are associated to a high morbidity and mortality [5] and some like the ones associated to atrial fibrillation (AF) and to a patent foramen ovale (PFO) have specific treatments that can reduce the risk of stroke recurrence. 
In this article, we aimed to perform a narrative review of the most recent literature regarding biomarkers associated to cardioembolic stroke. We searched studies that evaluated biomarkers associated to established cardioembolic etiologies like AF and PFO but also associated to emerging new possible causes of cardioembolic stroke, such as atrial cardiomyopathy and left ventricular wall motion abnormalities (LVWMA). We assessed biomarkers associated to diagnosis, prognosis, and stroke risk and recurrence.

\section{Atrial Fibrillation}

Atrial fibrillation is one of the main causes of cardioembolic stroke. Strokes related to AF are associated to a high morbidity and disability [5].

Current guidelines define presence of AF as electrocardiographic documentation of absolutely irregular RR intervals and no discernible, distinct $P$ waves lasting for at least $30 \mathrm{~s}$. However, there is no evidence to suggest that a run of AF lasting $>30 \mathrm{~s}$ is more important than several shorter episodes. On the other hand, our understanding of the risk factors and complications of AF is based mostly on studies that have evaluated AF in a binary fashion (present or absent) and have not investigated AF burden (quantity the cumulative amount of AF that an individual has). It is unclear whether the risk increases continuously or whether a threshold exists.

The diagnosis of paroxysmal AF may be challenging. To date, several studies explored the use of prolonged noninvasive and invasive cardiac monitoring devices to identify AF. Nevertheless, the current available methods to detect paroxysmal AF have low sensitivity. It remains elusive which is the best method and the duration of monitoring to detect paroxysmal AF. It is known that a 24-h ECG recording has a higher sensitivity for the diagnosis of paroxysmal AF than a routine 12 lead ECG. In a systematic review [6] the detection rate of paroxysmal AF by a $24-72 \mathrm{~h}$ ECG recording was of $4.6 \%$. Due to the low detection rate of this examination, there is some controversy regarding its clinical utility and its routine use in the etiological investigation of ischemic stroke [7]. Serial ECG assessments within the first $72 \mathrm{~h}$ of an acute stroke significantly improve detection of AF [8]. Automated analysis of continuous stroke unit ECG monitoring improves paroxysmal AF detection in patients with stroke on stroke units compared with 24-h Holter ECG [9].

Randomized clinical trials like CRISTAL-AF [10] and EMBRACE [11] showed that longer monitoring of the heart rhythm increased the probability of detecting atrial fibrillation in patients initially suspected of having a cryptogenic stroke (AF lasting $>30 \mathrm{~s}$ ). However, even in the CRISTAL-AF trial in which insertable cardiac monitors (ICM) were used the rate of atrial fibrillation detection did not surpass $12.4 \%$ of patients in the ICM group at 12 months [10].

A biomarker that could aid in the diagnosis of paroxysmal AF would be very helpful, namely to select patients that could benefit the most from long term heart rhythm monitoring. Several studies have analyzed possible biomarkers of AF. Most have analyzed levels of biomarkers in patients with known AF. Only a few have prospectively analyzed how biomarkers measured at baseline were predictive of AF.

\subsection{NT-proBNP and BNP}

\subsubsection{Atrial Fibrillation Diagnosis}

The majority of studies regarding possible biomarkers of $\mathrm{AF}$ in ischemic stroke refer to the N-terminal of the pro-brain natriuretic peptide (NT-proBNP) and the brain natriuretic peptide (BNP).

NT-proBNP is part of a group of natriuretic peptides, phylogenetically conserved along time that includes peptides such as atrial natriuretic peptide (ANP), natriuretic peptide type C, urodilatin and the Dendroaspis natriuretic peptide [12]. NT-proBNP is coded by a gene composed by three exons and two introns that is located in chromosome 1p36.2. It is initially produced as a prepropeptide of 143 amino acids. This prepropeptide is proteolytic cleaved into a non-active $\mathrm{N}$-terminal fragment composed by 108 amino acids designated proBNP. ProBNP after secretion is divided in two fractions by two proteolytic 
enzymes. These two fractions are BNP that is biological active (aa 77-108) and the Nterminal-proBNP (NT-proBNP) (aa 1-76) without biological activity [13]. BNP and NTproBNP concentrations can be determined in blood samples [14]. The half-life of these two peptides differs. NT-proBNP has a half-life superior to BNP. NT-proBNP has a half-life of $120 \mathrm{~min}$ and BNP a half-life of $22 \mathrm{~min}$ [15]. It is due to this difference in half-life that most essays measure NT-proBNP instead of BNP. In the heart, BNP can be produced by both atria and ventricles [16]. However, due to the larger ventricular mass, $70 \%$ of all $\mathrm{BNP}$ is produced by the ventricle in normal conditions [17].

Higher levels of NT-proBNP and BNP have been consistently shown to be present in patients with cardioembolic stroke associated to AF when compared to patients with a noncardioembolic etiology $[18,19]$. In the first $72 \mathrm{~h}$ after ischemic stroke, NT-proBNP serum levels have been shown to have a similar diagnostic accuracy to diagnose cardioembolic stroke, although NT-proBNP levels were highest in the first two days after ischemic stroke and declined significantly thereafter [20].

Several cut-off points for the diagnosis of cardioembolic stroke associated to AF have been proposed. The use of different methodologies and assay kits may hamper the establishment of a cut-off point that could be used in a generalized way. Although NT-proBNP and BNP levels tend to increase with age and differ according to gender, scarce studies searched for different cut-off points according to these characteristics [21]. Moreover, several conditions may increase NT-proBNP and BNP levels and be confounding factors. Therefore, it is important to recognize what pathologies can be associated to increased levels of natriuretic peptides. These include: acute ischemic heart disease, heart failure, heart valve disease, renal failure, anemia, acute pulmonary embolism, pulmonary hypertension, sepsis and hyperthyroidism [22]. Treatment with angiotensin-converting enzyme inhibitors (ACEI), Angiotensin II receptor blockers (ARB), diuretics and Betablockers can also increase NT-proBNP and BNP levels [22]. There is an inverse relationship between natriuretic peptide levels and obesity (body mass index $\geq 30$ ) [23].

Only some studies prospectively followed cryptogenic ischemic stroke patients to determine if NT-proBNP levels measured at baseline at the time of ischemic stroke onset could be predictors of a later diagnosis of AF [24]. In one study that analyzed serum levels of NT-proBNP, eighty patients with cryptogenic stroke were followed during six months to look for AF. In 17, paroxysmal AF was found during follow-up. In these patients, the area under the curve for the diagnosis of paroxysmal AF was 0.83. The cut-off point of $265.5 \mathrm{pg} / \mathrm{mL}$ had a sensitivity of $88.2 \%$ and a specificity of $61.9 \%$. The cutoff point of $912 \mathrm{pg} / \mathrm{mL}$ had a sensitivity of $47.1 \%$ and a specificity of $88.9 \%$ [24].

A systematic review with pooled meta-analysis that analysed NT-proBNP and BNP reported that BNP/NT-proBNP levels were significantly elevated in cardioembolic stroke. Predictive models showed a sensitivity $>90 \%$ and specificity $>80 \%$ when BNP/NT-proBNP were added considering the lowest and the highest quartile, respectively. Both peptides also significantly increased the area under the curve and integrated discrimination improvement index compared with clinical models [25].

A clinical trial is currently using NT-proBNP concentrations levels to decide upon further screening for AF [26]. The STROKESTOP II trial is a randomized, population-based study of AF screening in individuals older than 75. All individuals with NT-proBNP > $125 \mathrm{ng} / \mathrm{L}$ and without known AF are taught to undergo intermittent ECG recordings twice daily for two weeks (intervention group). Individuals with a NT-proBNP $<125 \mathrm{ng} / \mathrm{L}$ do one initial 1-lead ECG, and if normal do not undergo further ECG screening (control group). The primary outcome measure is the incidence of stroke or systemic embolism in the control group versus the intervention group [26].

\subsubsection{Stroke Recurrence}

A study that used data from the ENGAGE AF-TIMI 48 which was a randomized trial of the oral factor Xa inhibitor edoxaban in patients with AF and a CHADS2 score of $\geq 2$, evaluated NT-proBNP as a predictor of stroke recurrence in anticoagulated patients [27]. 
This studied included 6308 patients. In a Cox regression model, upward changes in log2transformed NT-proBNP were associated with increased risk of stroke or systemic embolic events in anticoagulated patients (adjusted hazard ratio (adj-HR) 1.74; 95\% confidence interval (CI) 1.36-2.23 and adj-HR 1.27; 95\% CI 1.07-1.50, respectively) [27].

\subsection{Atrial Natriuretic Peptide (ANP) and Midregional Fragment of the Precursor Hormone of ANP (MR-proANP)}

The Atrial natriuretic peptide (ANP) or atrial natriuretic factor (ANF) is a natriuretic peptide hormone secreted from the atria. As it is only produced by the atria in contrast to BNP and NT-proBNP that are both produced by atria and ventricles it could theoretically be a biomarker more accurate to diagnose AF. MR-proANP is a stable fragment of the ANP precursor hormone [28]. A retrospective study compared the diagnostic accuracy of ANP and BNP. Two-hundred and twenty-two consecutive ischemic stroke patients within $48 \mathrm{~h}$ after stroke onset were evaluated. Plasma ANP and BNP were simultaneously measured at admission. One hundred and fifty-eight patients had no evidence of $\mathrm{AF}, 25$ patients had paroxysmal AF, and the other 39 patients had chronic AF. ANP was significantly higher in the paroxysmal AF than in the sinus rhythm group $(97$ (50-157) $\mathrm{mg} / \mathrm{dL}$ versus $42(26-72) \mathrm{mg} / \mathrm{dL}, p<0.05)$ and further increased in the chronic AF group (228 (120-392), $p<0.05$ versus paroxysmal AF and sinus rhythm groups). Similarly, the BNP value was higher in the paroxysmal AF than in the sinus rhythm group (116 (70-238) $\mathrm{mg} / \mathrm{dL}$ versus $34(14-72) \mathrm{mg} / \mathrm{dL}, p<0.05)$ and further increased in the chronic AF group (269 (199-423) $p<0.05$ versus paroxysmal AF and sinus rhythm groups). The area under the curve was similar between ANP and BNP (0.76 and 0.80) [28].

In a prospective multicenter cohort study that quantified MR-proANP levels in ischemic stroke patients within $24 \mathrm{~h}$ of stroke onset, the diagnosis of AF at hospital discharge were associated with MR-proANP with an OR of 18.35 (95\% CI 7.94-42.45, $p<0.001$ ) [29]. The continuous net reclassification index of MR-proANP for AF was 78\%, 95\% CI 60\%-89\%, $p<0.001$ ). MR-proANP levels $\geq 289 \mathrm{pmol} / \mathrm{L}$ had a specificity of $86 \%$ and sensitivity of $48 \%$ for the diagnosis of AF.

\subsection{Interleukin-6}

IL-6 is an inflammatory cytokine with pleiotropic effects on immune response and inflammation. It is synthesized in immune cells such as macrophages and monocytes. Emerging studies have proved that inflammation plays a key role in AF. Thrombogenesis related to AF is also associated with inflammation [30].

A meta-analysis of five studies involving 22,928 patients showed that higher levels of IL-6 in AF patients are related to the risk of long-term thromboembolic events including stroke (RR 1.44, CI 95\% 1.09-1.90, $p=0.01$ ) [30]. A cut-off point of IL-6 needs to be defined.

\subsection{Growth Differentiation Factor-15, Cystatin and High Sensitive Cardiac Troponin}

A new biomarker-based risk score to improve the prognostication of major bleeding in patients with AF was developed by Hijazi et al. [31]. The authors developed and internally validated a new biomarker-based risk score for major bleeding in 14,537 patients with AF randomized to apixaban versus warfarin in the ARISTOTLE trial and externally validated it in 8468 patients with AF randomized to dabigatran versus warfarin in the RE-LY trial. Plasma samples for determination of candidate biomarker concentrations were obtained at randomization. The ABC-bleeding score, using age, history of bleeding, and three biomarkers (hemoglobin, high sensitive cardiac troponin (cTn-hs), and growth differentiation factor-15 (GDF-15) or cystatin C) was internally and externally validated and calibrated in large cohorts of patients with AF receiving anticoagulation therapy. The ABC-bleeding score performed better than the HAS-BLED and ORBIT scores [31]. GDF-15 is a marker of oxidative stress; cardiac troponin is linked to myocardial injury and cystatin $C$ is a marker of renal function.

An ABC-AF-stroke (age, biomarkers, prior stroke) has also been developed to improve prognostication of stroke in patients with AF. This score incorporates NT-proBNP and 
cTn-hs levels as biomarkers, age and history of prior stroke/transient ischemic attack. It was developed and internally validated in 14,701 patients with AF treated with oral anticoagulation [32]. Biomarkers levels were evaluated at baseline and patients were followed for a mean time of 1.9 years. An external validation was performed in 1400 patients with AF with a median follow-up of 3.4 years. This score had a better accuracy to predict stroke in patient with AF than the CHADS2DS2VASC score in the derivation and validation cohorts (AUC of 0.68 vs. $0.62 p<0.001$ and 0.66 vs. $0.58 p<0.001$ respectively) [32].

Some studies have reported higher values at hospital admission of troponins (Cardiac troponin I) in patients with cardioembolic stroke than in patients with non-cardioembolic stroke. However, these studies did not discriminate the subtypes of cardioembolic stroke that were included $[33,34]$.

\subsection{D-dimers}

D-dimers are a breakdown product of fibrin. Baseline elevated d-dimers levels ( $\geq 2 \mu \mathrm{g} / \mathrm{mL}$ ) were found to be associated to a higher risk of recurrent ischemic stroke in patients with AF with HR of $1.8095 \%$ CI 1.13-2.84, $p=0.012$ [35]. Some studies have shown that elevated d-dimer levels are an independent predictor of the presence of left atrial thrombus in patients with AF [36,37].

\subsection{Genetics Biomarkers}

RNAs present in the peripheral blood have been studied as potential biomarkers. Changes in RNA expression in the blood of patients with cardioembolic stroke could reflect inflammatory and prothrombotic changes specific to this stroke etiology [38]. Microarray and RNA sequencing or PCR with reverse transcription allow the study of noncoding and coding RNA transcripts. In a discovery-based study that collected blood samples from 76 acute ischemic stroke patients, using whole genome microarrays, a 37-gene profile was able to differentiate cardioembolic stroke due to AF from non-AF causes with $>90 \%$ sensitivity and specificity [38]. The identified genes reflected differences in inflammation between stroke subtypes. The major source of RNA in the blood is immune cells including leukocytes, neutrophils, and monocytes. This gene expression signature profile that was identified needs to be validated in future, independent, larger studies [38].

MicroRNAs (miRNAs) are single-stranded, non-protein-coding RNAs composed of approximately 22 nucleotides [39]. They are involved in the regulation of post-transcriptional gene expression by binding with the target mRNA at the $3^{\prime}$ untranslated region. Changes in miRNA expression level are reported to be associated to different pathologies (39). The modulation of miRNA expression has been reported to reduce or increase the susceptibility to develop AF in vivo. This may be due to the regulation of atrial remodeling mechanisms by miRNAs [39]. miRNAs could therefore not only be a biomarker but also a potential therapeutic agent for the treatment of AF [40].

\section{Treatment Implications}

Biomarkers associated to the diagnosis of AF could be useful to select patients that could benefit the most from long term heart monitoring. The ideal way to test this possible application would be through a clinical trial, as is currently being tested in STROKESTOP II [26].

The accuracy of established risk scores for stroke, such as the CHA2-DS2-VASc score and the HAS-BLED could potentially be further improved by the addition of serum/ plasma biomarkers.

\section{Patent Foramen Ovale}

The foramen ovale is a flap-like communication between the right and the left atria at the level of the fossa ovalis, which is present in the fetus and enables the venous blood to bypass the non-functioning fetal lung and go directly to the left side of the heart [41]. The communication usually closes after birth however if the foramen persists after the 
age of one, it is called a patent foramen ovale (PFO). It can be found in up to $27 \%$ of the general population [41]. Case-control studies demonstrated an association between PFO and cryptogenic stroke (OR 2.9) especially in young adults ( $<55$ years of age) $[41,42]$. In the last years, results of clinical trials reported a consistently higher benefit of PFO closure compared to antiplatelet therapy in patients with an atrial septal aneurysm or large right-to-left shunts [41]. Some studies were conducted to analyze how biomarkers may help in the diagnosis of PFO or to predict the size of the right-to-left shunt or ischemic stroke recurrence.

\subsection{L-Arginine/Asymmetric Dimethylarginine Ratio}

Sgarra et al. evaluated the correlation, in terms of severity, between the degree of endothelial dysfunction assessed by the L-Arginine/asymmetric dimethylarginine ratio (L-Arg/ADMA ratio), the methylene tetrahydrofolate reductase (MTHFR) genotype, and the interatrial septum (IAS) phenotype in subject with a history of stroke [43]. L-arginine is the substrate for NO generation and asymmetric dimethylarginine (ADMA), an endogenous inhibitor of nitric oxide (NO) synthase. The study included 57 patients, and 10 had a septum integrum (SI), 38 a PFO, and nine an ostium secundum (OS). In the PFO subgroup a negative correlation was found between the L-Arg/ADMA ratio and PFO tunnel length/height ratio $\left(p \leq 0.05 ; \mathrm{r}=-0.37 ; \mathrm{R}^{2}=0.14\right)$. The authors suggest that the L-Arg/ADMA ratio could be used as a reliable marker of stroke susceptibility in carriers of an interatrial septum abnormalities, hinting at its potential use both as a diagnostic tool and as a decision aid for therapy [43].

\subsection{Homocysteine}

The 10-point risk of paradoxical embolism (RoPE) score is an index that was created to stratify cryptogenic stroke patients with PFO by their likelihood that the stroke was related to their PFO [44]. Zuin et al. found a direct correlation between serum homocysteine levels and the RopE score in a sample of $244 \mathrm{PFO}$ patients [45]. A receiver operating curve identified the optimal cutoff value of $19.5 \mu \mathrm{g} / \mathrm{dL}$ for homocysteinemia as a predictor of a high RoPE score $>7$ in the group of patients with PFO that underwent a closure procedure (AUC 0.90, 95\% CI 0.81-0.94, $p<0.0001$ ). Multivariate logistic regression analysis demonstrated that a homocysteine serum level $\geq 19.5 \mu \mathrm{g} / \mathrm{dL}$ predicted a RoPE score $>7$ (OR 3.21, 95\% CI 2.82-3.26, $p<0.0001$ ) in closed patients independently from the presence of a permanent right-to-left shunt (OR 2.28, 95\% CI 2.01-2.43, $p=0.001$ ) and atrial septal aneurysm (OR 3.04, 95\% CI 2.64-3.51, $p<0.0001)$ [45].

\subsection{D-dimers}

Kim et al. [46] followed 241 patients with PFO for a mean time of $34.0 \pm 22.8$ months. During follow-up, all-cause death occurred in $58(10.2 \%)$ patients, ischaemic stroke in $33(5.8 \%)$, and pulmonary thromboembolism in $6(1.1 \%)$. Multivariate Cox regression analysis showed that a D-dimer level of $>1000 \mathrm{ng} / \mathrm{mL}$ was an independent predictor for recurrent ischaemic stroke in patients with PFO (hazard ratio 5.341, 95 \% CI1.648-17.309, $p=0.005)$, but not in those without a PFO.

\section{Treatment Implications}

None of the biomarkers that was reported in the studies analyzed was further validated. Therefore, none can be used in clinical practice.

\section{Atrial Cardiomyopathy}

\subsection{Introduction}

Atrial cardiomyopathy, as defined by a consensus expert group in 2016, consists of any complex of structural, architectural, contractile or electrophysiological changes affecting the atria with the potential to produce clinically-relevant manifestations [47]. This new definition was a landmark and expanded the concept of cardioembolism, including primary 
atrial disorders as well as providing a framework for integrating the effects of diverse upstream cardiac and systemic disorders that induce secondary atrial remodeling [48].

The actual prevalence of atrial cardiomyopathy is unknown but the extensive list of associated predisposing factors, such as aging, high blood pressure, obesity, diabetes mellitus, and obstructive sleep apnea, suggest that this is a frequently encountered and important clinical condition $[47,48]$. Furthermore, there is growing evidence that supports the role of atrial cardiomyopathy as an independent determinant of stroke risk, particularly of embolic stroke subtypes [47,49-51]. Several biomarkers of left atrial dysfunction have been proposed for the diagnosis of atrial cardiopathy, with most of the literature referring to left atrial size (left atrial enlargement), $\mathrm{P}$ wave dispersion, $\mathrm{P}$-wave terminal force in lead V1 on EKG, paroxysmal supraventricular tachycardia, atrial high rate episodes, atrial fibrosis, and elevation of serum biomarkers associated with atrial dysfunction like NTproBNP [52-54]. However, it should be noted that some of these biomarkers are not specific to atrial dysfunction [52].

\subsection{NT-proBNP}

N-Terminal pro-Brain Natriuretic Peptide (NT-proBNP) has been shown to be associated with ischemic stroke, particularly cardioembolic stroke, independently of AF [55-57]

In a study that used the SPOTRIAS dataset, among 40 patients with cryptogenic stroke, $63 \%$ had atrial cardiopathy as evidenced by the presence of at least one of the biomarkers previously described. The most common finding was an elevation of NTproBNP $>250 \mathrm{pg} / \mathrm{mL}$, present in $49 \%$ of cryptogenic stroke patients [58].

Although there is concurrent evidence that a NT-proBNP elevation is associated to an increased likelihood of detecting paroxysmal AF in patients with ischemic stroke [59], bearing in mind that with prolonged heart rhythm monitoring AF detection increases up to $15-30 \%$ in cryptogenic stroke $[10,11]$, that could imply that $19-34 \%$ of patients may have an atrial cardiopathy without AF. The proportion of NT-proBNP elevation is probably not solely explained by the effect that AF can have on NT-proBNP elevation, highlighting the potential of NT-proBNP in atrial cardiopathy and cryptogenic stroke.

\subsection{Genetics Biomarkers/Genetic Diseases Associated to Atrial Cardiomyopathy}

Variants in genes that are functionally active in the cardiac atria and that contribute to atrial development and/or maintenance of atrial electrical, structural, and metabolic properties may directly cause or modify susceptibility to atrial cardiomyopathy [48].

However, the role of genetics in atrial cardiomyopathy is still in its infancy, and is mostly useful in families with Mendelian forms of disease. For most people, the role of genetics for the prediction of individualized risk of atrial cardiomyopathy and adverse outcomes such as AF has yet to be established [48].

\subsubsection{Natriuretic Peptide Precursor A Gene}

The natriuretic Peptide Precursor A (NPPA) gene is responsible for the expression of the atrial natriuretic peptide (ANP), an important molecule involved in atrial electric remodelling prevention; intravascular blood volume and vascular tone regulation and ion channel function regulation [60]. Fluctuations in ANP expression due to gene mutations can disturb these mechanisms, contributing to atrial dysfunction. Indeed, atrial dilated cardiomyopathy has been identified in patients with homozygous mutation in NPPA, presenting with severely decreased levels of ANP and with clinical onset in adulthood of biatrial dilatation, early supraventricular arrhythmias with progressive loss of atrial electric activity to atrial standstill and secondary thromboembolic complications, while having a stable normal left ventricular function and long-term stable functional class [46,61]. Patients with this condition require pacemaker or cardioverter defibrillator implantation and chronic anticoagulation because of the high prevalence of thromboembolic complications, most of them consisting of cerebral embolic episodes [61]. 


\subsubsection{Myosin Light-Chain 4 Gene}

Myosin light-chain 4 gene (MYL4) encodes the atrial-selective essential myosin light chain. This essential myosin light chain is also known as atrial light chain 1 , and is expressed in cardiac and skeletal muscle of the fetus and in the atria after birth, being a key sarcomeric component and important atrial specific contractile protein [62,63]. Mutations in MYL4 gene have been implicated in a primary atrial cardiomyopathy characterized by atrial selective abnormalities associated with conduction system disease, stroke, and eventually mild ventricular dysfunction [62,63]. At least three kindreds have been described: an Icelandic kindred presenting with atrial cardiomyopathy, with a frameshift mutation in MYL4 associated with early-onset familial AF and bradyarrhythmias requiring pacemaker insertion, ischaemic stroke and sudden death [62], a Canadian kindred presenting with early-onset $\mathrm{AF}$, conduction disease and reduced left atrial function as measured by left atrial function index [64], and a Chinese kindred presenting with an inherited atrial cardiomyopathy and atrial standstill as a prominent feature, evolving from contractile abnormalities at a young age, followed by atrial arrhythmia, atrioventricular block, and finally total atrial standstill [65].

Therapeutical Implications of Atrial Cardiomyopathy

Atrial cardiopathy can be an important cause of cryptogenic stroke and this emerging concept can have important therapeutical implications [66]. The evaluation of atrial cardiopathy can identify patients with a thromboembolic prone left atrium, which could lead to a cardioembolic stroke in the absence of AF $[50,66,67]$. Taking this into account, anticoagulant therapies may well be of benefit for stroke prevention in a wider population of patients than just those with AF. Preliminary evidence of this effect can be seen in an analysis of the WARSS trial, in which a subgroup of patients with elevated NT-proBNP had a substantially lower risk of recurrent stroke or death when treated with warfarin rather than aspirin [57]. This result will be further elucidated trials such as the ARCADIA and ATTICUS trial, which could prove the potential role of oral anticoagulation (apixaban versus aspirin) for patients with cryptogenic stroke and atrial cardiopathy $[66,67]$. To be included in the ARCADIA trial patients have to fulfill at least one of three criteria which include a Serum NT-proBNP $>250 \mathrm{pg} / \mathrm{mL}$ (NT-proBNP criterion), P-wave terminal force $>$ $5000 \mathrm{uv} x \mathrm{~ms}$ in ECG lead V1, and left atrial diameter index $\geq 3 \mathrm{~cm} / \mathrm{m}^{2}$. The ATTICUS trial that will compare apixaban versus aspirin to prevent ischemic stroke recurrence does not used serum biomarkers but electrocardiographic and echocardiogram parameters suggestive of atrial cardiomyopathy to include patients namely one of the following: LA size $>45 \mathrm{~mm}$ (parasternal axis), spontaneous echo contrast in the left atrial appendage (LAA), LAA flow velocity $\leq 0.2 \mathrm{~m} / \mathrm{s}$, atrial high rate episodes, CHADSDS2-vass score $\geq 4$, FPO [67].

\section{Left Ventricular Wall Motion Abnormalities}

Left ventricular wall motion abnormalities (LVWMA) are a common finding detected on echocardiographic evaluation of stroke patients. These changes are related with various pathologies, such as coronary artery disease, congestive heart failure, stress-induced cardiomyopathy, myocarditis or chronic renal disease [68]. It is believed that left ventricular akinetic or hypokinetic segments could lead to a vulnerable environment where thromboembolism may occur, induced by regional blood stasis and incomplete ventricular emptying [66,69]. However, LVWMA role in stroke is still uncertain [67].

\subsection{NT-proBNP}

There is evidence relating NT-proBNP elevations and cardioembolic stroke $[15,16]$. However, its applicability for determining the presence of LVWMA is less well established. Hosomi et al. studied the levels of BNP and particular left ventricle segment asynergy in patients who had an ischaemic stroke and had a previous history of an old myocardial infarction [70]. Patients with AF were excluded, and based on their results, cardioembolic 
stroke was associated with a high plasma BNP level, independently of a left ventricular ejection fraction less than $40 \%$ [70]. High plasma BNP levels $(>206.9 \mathrm{pg} / \mathrm{mL})$ and left ventricular wall motion abnormalities in the segments perfused by the left anterior descending coronary artery or right coronary artery showed a high risk for cardioembolic stroke in patients with old myocardial infarction.

\subsection{Genetics}

LVWMA can be found in patients with cardiac pathology, namely in familial cardiomyopathies such as hypertrophic cardiomyopathy and dilated cardiomyopathy [71,72]. Hypertrophic cardiomyopathy (HCM) is a genetically determined heart muscle disease that is inherited in an autosomal dominant pattern in more than $90 \%$ of cases [73]. Over 1500 mutations in at least 15 sarcomere-encoding genes have been identified [74]. About $70 \%$ of these mutations are in the sarcomere genes encoding cardiac $\beta$-myosin heavy chain (MYH7) and cardiac myosin binding protein C (MYBPC3) [73]. Mutations in troponin $\mathrm{T}$ (TNNT2), troponin I (TNNI3), and $\alpha$-tropomyosin (TPM1) are relatively uncommon causes of HCM and together are responsible for less than $10 \%$ of cases [75,76]. Mutations in cardiac $\alpha$-actin A(CTC1), myosin light chain 2 (MYL2), myosin light chain 3 (MYL3), and Cysteine and Glycine Rich Protein 3 (CSRP3) are other known rare causes of HCM [75].

Dilated cardiomyopathy (DCM) is a heart-muscle disorder characterized by systolic dysfunction and dilatation of the left ventricle with normal left ventricular wall thickness [77]. Familial genetic forms of DCM represent $20-40 \%$ of patients [77,78]. Up to 40 genes have been implied in DCM, inherited primarily in an autosomal dominant pattern $[77,79]$. These genes encode for a wide variety of proteins of the sarcomere, cytoskeleton, nuclear envelope, sarcolemma, ion channels and intercellular junctions [77]. The most common mutations involve sarcomere proteins, in particular titin (TTN) truncating mutations, which are responsible for $25 \%$ of familial DCM [77]. Other sarcomere genes mutated in DCM are MYH7 (encoding myosin 7, also known as $\beta$-myosin heavy chain), MYH6 (encoding myosin 6 , also known as $\alpha$-myosin heavy chain), MYBPC3 (encoding cardiac-type myosin-binding protein C), TNNT2, TNNI3, TPM1, MYL2, MYL3 and ACTC1. The most common gene mutated involving nuclear envelope is LMNA, encoding the intermediate filament proteins lamins $\mathrm{A}$ and $\mathrm{C}$ and responsible for $8 \%$ of familial DCM [77-79].

\section{Therapeutical Implications of Left Ventricular Wall Motion Abnormalities}

Left ventricular wall motion abnormalities are an important finding in echocardiographic study of ischaemic stroke patients and may be an independent predictor of stroke recurrence [68,69]. Moreover, LVWMA can present as an echocardiographic finding due to previous cardiac disease, namely myocardial infarction. Anterior apical MI is more likely to result in LV thrombus formation and is associated with cerebral embolism [80]. The detailed role of LVWMA could be assessed in trials evaluating direct oral anticoagulants for prevention of stroke recurrence or systemic embolism in patients with embolic stroke of undetermined source, especially in the analysis of subpopulations with LVWMA.

\section{Conclusions}

Several biomarkers related to cardioembolism are currently being studied (Table 1).

However, NT-proBNP and BNP are still the biomarkers that have been most studied in the context of cardioembolic stroke and for which more evidence exists. Various studies and meta-analysis evaluated these substances as biomarkers of cardioembolic stroke or as predictors of AF. More recently, NT-proBNP and BNP have been used in clinical trials for the selection of patients. These peptides also are starting to be incorporated in risk prediction scores. The majorities of other substances that are currently being evaluated as biomarkers related to cardioembolism, however, are far from being able to be used in clinical trials. This is mainly due to the low methodological quality of most of these studies. Frequently, only a small number of patients are included ( $<100$ patients), and the number of studies that have either an internal or external validation of the cut-off points is 
very low. Greater adherence to methodological criteria could help to translate results to clinical practice.

Table 1. Summary of biomarkers related to cardioembolic sources and the application in which they are currently being evaluated.

\begin{tabular}{|c|c|c|}
\hline Cardioembolic Source & Biomarker & Studied Application \\
\hline \multirow{8}{*}{ Atrial fibrillation } & \multirow{2}{*}{ NT-proBNP/ BNP } & Diagnosis \\
\hline & & Stroke recurrence \\
\hline & ANP/MR-proANP & Diagnosis \\
\hline & GDF-15 & Major bleeding \\
\hline & cTn-hs & $\begin{array}{c}\text { Stroke risk } \\
\text { Major bleeding }\end{array}$ \\
\hline & IL-6 & Stroke risk \\
\hline & D-dimers & Stroke recurrence \\
\hline & RNA & Diagnosis \\
\hline \multirow{3}{*}{ Patent foramen ovale } & L-Arginine/asymmetricdimethylarginine ratio & Stroke risk \\
\hline & Homocysteine & Stroke risk \\
\hline & D-dimers & Stroke recurrence \\
\hline \multirow{3}{*}{ Atrial cardiomyopathy } & NT-proBNP & Diagnosis \\
\hline & NNPA & Diagnosis \\
\hline & MYL4 & Diagnosis \\
\hline \multirow{2}{*}{ Left ventricular wall motion abnormalities } & NT-proBNP & Stroke risk \\
\hline & Genetic markers & Diagnosis \\
\hline
\end{tabular}

Author Contributions: Conceptualization, A.C.F.; methodology, A.C.F. and P.C.; writing-original draft preparation, P.C.; writing-review and editing, A.C.F. and P.C. Both authors have read and agreed to the published version of the manuscript.

Funding: This research received no external funding.

Institutional Review Board Statement: Not applicable.

Informed Consent Statement: Not applicable.

Conflicts of Interest: The authors declare no conflict of interest.

\section{References}

1. Jørgensen, J.T. Predictive biomarkers and clinical evidence. Basic Clin. Pharmacol. Toxicol. 2021, 128, 642-648. [CrossRef]

2. Dagonnier, M.; Donnan, G.A.; Davis, S.M.; Dewey, H.M.; Howells, D.W. Acute Stroke Biomarkers: Are We There Yet? Front. Neurol. 2021, 12, 619721. [CrossRef] [PubMed]

3. Whiteley, W.; Tseng, M.C.; Sandercock, P. Blood biomarkers in the diagnosis of ischemic stroke: A systematic review. Stroke 2008, 39, 2902-2909. [CrossRef] [PubMed]

4. Fonseca, A.C.; Ferro, J.M. Cryptogenic stroke. Eur. J. Neurol. 2015, 22, 618-623. [CrossRef] [PubMed]

5. Hayden, D.T.; Hannon, N.; Callaly, E.; Ni Chroinin, D.; Horgan, G.; Kyne, L.; Duggan, J.; Dolan, E.; O’Rourke, K.; Williams, D.; et al. Rates and determinants of 5-year outcomes after atrial fibrillation-related stroke: A population study. Stroke 2015, 46, 3488-3493. [CrossRef]

6. Liao, J.; Khalid, Z.; Scallan, C.; Morillo, C.; O’Donnell, M. Noninvasive cardiac monitoring for detecting paroxysmal atrial fibrillation or flutter after acute ischemic stroke: A systematic review. Stroke 2007, 38, 2935-2940. [CrossRef] [PubMed]

7. Schaer, B.; Sticherling, C.; Lyrer, P.; Osswald, S. Cardiological diagnostic workup in stroke patients-A comprehensive study of test results and therapeutic implications. Eur. J. Neurol. 2009, 16, 268-273. [CrossRef]

8. Douen, A.G.; Pageau, N.; Medic, S. Serial electrocardiographic assessments significantly improve detection of atrial fibrillation 2.6-fold in patients with acute stroke. Stroke 2008, 39, 480-482. [CrossRef] 
9. Rizos, T.; Güntner, J.; Jenetzky, E.; Marquardt, L.; Reichardt, C.; Becker, R.; Reinhardt, R.; Hepp, T.; Kirchhof, P.; Aleynichenko, E.; et al. Continuous stroke unit electrocardiographic monitoring versus 24-hour Holter electrocardiography for detection of paroxysmal atrial fibrillation after stroke. Stroke 2012, 43, 2689-2694. [CrossRef]

10. Sanna, T.; Diener, H.C.; Passman, R.S.; Di Lazzaro, V.; Bernstein, R.A.; Morillo, C.A.; Rymer, M.M.; Thijs, V.; Rogers, T.; Beckers, F.; et al. Cryptogenic stroke and underlying atrial fibrillation. N. Engl. J. Med. 2014, 370, 2478-2486. [CrossRef] [PubMed]

11. Gladstone, D.J.; Spring, M.; Dorian, P.; Panzov, V.; Thorpe, K.E.; Hall, J.; Vaid, H.; O’Donnell, M.; Laupacis, A.; Côté, R.; et al. Atrial fibrillation in patients with cryptogenic stroke. N. Engl. J. Med. 2014, 370, 2467-2477. [CrossRef] [PubMed]

12. Rose, R.; Giles, W. Natriuretic peptide C receptor signaling in the heart and vasculature. J. Physiol. 2008, 586, 353-366. [CrossRef] [PubMed]

13. Sudoh, T.; Minamino, N.; Kangawa, K.; Matsuo, H. C-type natriuretic peptide (CNP): A new member of natriuretic peptide family identified in porcine brain. Biochem. Biophys. Res. Commun. 1990, 168, 863-870. [CrossRef]

14. Lam, C.S.; Burnett, J.C., Jr.; Costello-Boerrigter, L.; Rodeheffer, R.J.; Redfield, M.M. Alternate circulating pro-B-type natriuretic peptide and B-type natriuretic peptide forms in the general population. J. Am. Coll. Cardiol. 2007, 49, 1193-1202. [CrossRef] [PubMed]

15. Valli, N.; Gobinet, A.; Bordenave, L. Review of 10 years of the clincal use of brain natriuretic peptide in cardiology. J. Lab. Clin. Med. 1999, 134, 437-444. [CrossRef]

16. Yasue, H.; Yoshimura, M.; Sumida, H.; Kikuta, K.; Kugiyama, K.; Jougasaki, M.; Ogawa, H.; Okumura, K.; Mukoyama, M.; Nakao, K. Localization and mechanism of secretion of B-type natriuretic peptide in comparison with those of A-type natriuretic peptide in normal subjects and patients with heart failure. Circulation 1994, 90, 195-203. [CrossRef]

17. Mukoyama, M.; Nakao, K.; Saito, Y.; Ogawa, Y.; Hosoda, K.; Suga, S.; Shirakami, G.; Jougasaki, M.; Imura, H. Human brain natriuretic peptide, a novel cardiac hormone. Lancet 1990, 335, 801-802. [CrossRef]

18. Fonseca, A.C.; Matias, J.S.; Pinho e Melo, T.; Falcão, F.; Canhão, P.; Ferro, J.M. N-terminal probrain natriuretic peptide as a biomarker of cardioembolic stroke. Int. J. Stroke 2011, 6, 398-403. [CrossRef]

19. Zhao, J.; Zhang, Y.; Yuan, F.; Song, C.; Jiang, Y.; Gao, Q.; Leng, X.; Jiang, W. Diagnostic value of N-terminal pro B-type natriuretic peptide for nonvalvular atrial fibrillation in acute ischemic stroke patients: A retrospective multicenter case-control study. $J$. Neurol. Sci. 2020, 414, 116822. [CrossRef]

20. Fonseca, A.C.; Matias, J.S.; EMelo, T.P.; Pires, C.; Geraldes, R.; Canhão, P.; Brito, D.; Ferro, J.M. Time course of NT-proBNP levels after acute ischemic stroke. Acta Neurol. Scand. 2013, 128, 235-240. [CrossRef]

21. Teixeira, J.; Guillaume, M.; Nellessen, E.; Chapelle, J.P. BNP et NT-proBNP: Valeurs de référence et seuils décisionnels [BNP and NT-proBNP: Reference values and cutoff limits]. Rev. Med. Liege 2012, 67, 38-43. [PubMed]

22. Daniels, L.B.; Maisel, A. Natriuretic peptides 2007. J. Am. Coll. Cardiol. 2007, 50, 2357-2368. [CrossRef] [PubMed]

23. Madamanchi, C.; Alhosaini, H.; Sumida, A.; Runge, M.S. Obesity and natriuretic peptides, BNP and NT-proBNP: Mechanisms and diagnostic implications for heart failure. Int. J. Cardiol. 2014, 176, 611-617. [CrossRef] [PubMed]

24. Fonseca, A.C.; Brito, D.; Pinho e Melo, T.; Geraldes, R.; Canhão, P.; Caplan, L.R.; Ferro, J.M. N-terminal pro-brain natriuretic peptide shows diagnostic accuracy for detecting atrial fibrillation in cryptogenic stroke patients. Int. J. Stroke 2014, 9, 419-425. [CrossRef]

25. Llombart, V.; Antolin-Fontes, A.; Bustamante, A.; Giralt, D.; Rost, N.S.; Furie, K.; Shibazaki, K.; Biteker, M.; Castillo, J.; RodríguezYáñez, M.; et al. B-type natriuretic peptides help in cardioembolic stroke diagnosis: Pooled data meta-analysis. Stroke 2015, 46, 1187-1195. [CrossRef]

26. Systematic NT-proBNP and ECG Screening for Atrial Fibrillation among 75 Year Old Subjects in the Region of Stockholm, Sweden-STROKESTOP II (STROKESTOP II). Available online: https:/ / clinicaltrials.gov / ct2/show / NCT02743416 (accessed on 19 April 2021).

27. Oyama, K.; Giugliano, R.P.; Berg, D.D.; Ruff, C.T.; Jarolim, P.; Tang, M.; Murphy, S.A.; Lanz, H.J.; Grosso, M.A.; Antman, E.M.; et al. Serial assessment of biomarkers and the risk of stroke or systemic embolism and bleeding in patients with atrial fibrillation in the ENGAGE AF-TIMI 48 trial. Eur. Heart J. 2021, 42, 1698-1706. [CrossRef]

28. Katan, M.; Fluri, F.; Schuetz, P.; Morgenthaler, N.G.; Zweifel, C.; Bingisser, R.; Kappos, L.; Steck, A.; Engelter, S.T.; Müller, B.; et al. Midregional pro-atrial natriuretic peptide and outcome in patients with acute ischemic stroke. J. Am. Coll. Cardiol. 2010, 56, 1045-1053. [CrossRef]

29. De Marchis, G.M.; Schneider, J.; Weck, A.; Fluri, F.; Fladt, J.; Foerch, C.; Mueller, B.; Luft, A.; Christ-Crain, M.; Arnold, M.; et al. Midregional proatrial natriuretic peptide improves risk stratification after ischemic stroke. Neurology 2018, 90, e455-e465. [CrossRef]

30. Zhou, P.; Waresi, M.; Zhao, Y.; Lin, H.C.; Wu, B.; Xiong, N.; Li, H.; Huang, Q.; Luo, X.; Li, J. Increased serum interleukin-6 level as a predictive biomarker for atrial fibrillation: A systematic review and meta-analysis. Rev. Port Cardiol. 2020, 39, 723-728. [CrossRef]

31. Hijazi, Z.; Oldgren, J.; Lindbäck, J.; Alexander, J.H.; Connolly, S.J.; Eikelboom, J.W.; Ezekowitz, M.D.; Held, C.; Hylek, E.M.; Lopes, R.D.; et al. The novel biomarker-based ABC (age, biomarkers, clinical history)-bleeding risk score for patients with atrial fibrillation: A derivation and validation study. Lancet 2016, 387, 2302-2311. [CrossRef] 
32. Hijazi, Z.; Lindbäck, J.; Alexander, J.H.; Hanna, M.; Held, C.; Hylek, E.M.; Lopes, R.D.; Oldgren, J.; Siegbahn, A.; Stewart, R.A.; et al. The ABC (age, biomarkers, clinical history) stroke risk score: A biomarker-based risk score for predicting stroke in atrial fibrillation. Eur. Heart J. 2016, 37, 1582-1590. [CrossRef] [PubMed]

33. Nisar, T.; Kamin, S. Association of Serum Troponin Obtained During Stroke Codes with Cardioembolic Strokes. J. Stroke Cerebrovasc. Dis. 2020, 29, 104527. [CrossRef]

34. Yaghi, S.; Chang, A.D.; Ricci, B.A.; Jayaraman, M.V.; McTaggart, R.A.; Hemendinger, M.; Narwal, P.; Dakay, K.; Mac Grory, B.; Cutting, S.M.; et al. Early Elevated Troponin Levels after Ischemic Stroke Suggests a Cardioembolic Source. Stroke 2018, 49, 121-126. [CrossRef]

35. Choi, K.H.; Seo, W.K.; Park, M.S.; Kim, J.T.; Chung, J.W.; Bang, O.Y.; Kim, G.M.; Song, T.J.; Kim, B.J.; Heo, S.H.; et al. Baseline D-Dimer Levels as a Risk Assessment Biomarker for Recurrent Stroke in Patients with Combined Atrial Fibrillation and Atherosclerosis. J. Clin. Med. 2019, 8, 1457. [CrossRef]

36. Tarnowski, D.; Poitz, D.M.; Plichta, L.; Heidrich, F.M.; Wiedemann, S.; Ruf, T.; Mierke, J.; Löhn, T.; Jellinghaus, S.; Strasser, R.H.; et al. Comparison of diverse platelet activation markers as indicators for left atrial thrombus in atrial fibrillation. Platelets 2018, 29, 41-47. [CrossRef]

37. Almorad, A.; Ohanyan, A.; Pintea Bentea, G.; Wielandts, J.Y.; El Haddad, M.; Lycke, M.; O’Neill, L.; Morissens, M.; De Keyzer, E.; Nguyen, T; et al. D-dimer blood concentrations to exclude left atrial thrombus in patients with atrial fibrillation. Heart 2021, 107, 195-200. [CrossRef] [PubMed]

38. Jickling, G.C.; Xu, H.; Stamova, B.; Ander, B.P.; Zhan, X.; Tian, Y.; Liu, D.; Turner, R.J.; Mesias, M.; Verro, P.; et al. Signatures of cardioembolic and large-vessel ischemic stroke. Ann. Neurol. 2010, 68, 681-692. [CrossRef]

39. Komal, S.; Yin, J.J.; Wang, S.H.; Huang, C.Z.; Tao, H.L.; Dong, J.Z.; Han, S.N.; Zhang, L.R. MicroRNAs: Emerging biomarkers for atrial fibrillation. J. Cardiol. 2019, 74, 475-482. [CrossRef] [PubMed]

40. Neudecker, V.; Brodsky, K.S.; Kreth, S.; Ginde, A.A.; Eltzschig, H.K. Emerging Roles for MicroRNAs in Perioperative Medicine. Anesthesiology 2016, 124, 489-506. [CrossRef]

41. Miranda, B.; Fonseca, A.C.; Ferro, J.M. Patent foramen ovale and stroke. J. Neurol. 2018, 265, 1943-1949. [CrossRef]

42. Alsheikh-Ali, A.A.; Thaler, D.E.; Kent, D.M. Patent foramen ovale in cryptogenic stroke: Incidental or pathogenic? Stroke 2009, 40, 2349-2355. [CrossRef]

43. Sgarra, L.; Bortone, A.S.; Potenza, M.A.; Nacci, C.; De Salvia, M.A.; Acquaviva, T.; De Cillis, E.; Ciccone, M.M.; Grimaldi, M.; Montagnani, M. Endothelial Dysfunction May Link Interatrial Septal Abnormalities and MTHFR-Inherited Defects to Cryptogenic Stroke Predisposition. Biomolecules 2020, 10, 861. [CrossRef]

44. Kent, D.M.; Ruthazer, R.; Weimar, C.; Mas, J.L.; Serena, J.; Homma, S.; Di Angelantonio, E.; Di Tullio, M.R.; Lutz, J.S.; Elkind, M.S.; et al. An index to identify stroke-related vs. incidental patent foramen ovale in cryptogenic stroke. Neurology 2013, 81, 619-625. [CrossRef]

45. Zuin, M.; Rigatelli, G.; Rigatelli, A.; Ronco, F.; Conte, L.; Roncon, L.; Mazza, A. Correlations between serum homocysteine levels and RoPE score in patients with patent foramen ovale. Heart Vessels. 2020, 35, 705-711. [CrossRef]

46. Kim, Y.D.; Song, D.; Nam, H.S.; Lee, K.; Yoo, J.; Hong, G.R.; Lee, H.S.; Nam, C.M.; Heo, J.H. D-dimer for prediction of long-term outcome in cryptogenic stroke patients with patent foramen ovale. Thromb. Haemost. 2015, 114, 614-622. [CrossRef]

47. Goette, A.; Kalman, J.M.; Aguinaga, L.; Akar, J.; Cabrera, J.A.; Chen, S.A.; Chugh, S.S.; Corradi, D.; D’Avila, A.; Dobrev, D.; et al. EHRA/HRS/APHRS/SOLAECE expert consensus on atrial cardiomyopathies: Definition, characterization, and clinical implication. Europace 2016, 18, 1455-1490. [CrossRef]

48. Fatkin, D.; Huttner, I.G.; Johnson, R. Genetics of atrial cardiomyopathy. Curr. Opin. Cardiol. 2019, 34, 275-281. [CrossRef]

49. Fonseca, A.C.; Ferro, J.M.; Almeida, A.G. Cardiovascular magnetic resonance imaging and its role in the investigation of stroke: An update. J. Neurol. 2021. [CrossRef] [PubMed]

50. Fonseca, A.C.; Alves, P.; Inácio, N.; Marto, J.P.; Viana-Baptista, M.; Pinho-E-Melo, T.; Ferro, J.M.; Almeida, A.G. Patients With Undetermined Stroke Have Increased Atrial Fibrosis: A Cardiac Magnetic Resonance Imaging Study. Stroke 2018, 49, 734-737. [CrossRef] [PubMed]

51. Sebasigari, D.; Merkler, A.; Guo, Y.; Gialdini, G.; Kummer, B.; Hemendinger, M.; Song, C.; Chu, A.; Cutting, S.; Silver, B.; et al. Biomarkers of Atrial Cardiopathy and Atrial Fibrillation Detection on Mobile Outpatient Continuous Telemetry after Embolic Stroke of Undetermined Source. J. Stroke Cerebrovasc. Dis. 2017, 26, 1249-1253. [CrossRef]

52. Yaghi, S.; Kamel, H.; Elkind, M.S.V. Atrial cardiopathy: A mechanism of cryptogenic stroke. Expert Rev. Cardiovasc. Ther. 2017, 15, 591-599. [CrossRef] [PubMed]

53. Kamel, H.; Okin, P.M.; Longstreth, W.T., Jr.; Elkind, M.S.; Soliman, E.Z. Atrial cardiopathy: A broadened concept of left atrial thromboembolism beyond atrial fibrillation. Future Cardiol. 2015, 11, 323-331. [CrossRef] [PubMed]

54. Khan, A.A.; Boriani, G.; Lip, G.Y.H. Are atrial high rate episodes (AHREs) a precursor to atrial fibrillation? Clin. Res. Cardiol. 2020, 109, 409-416. [CrossRef]

55. Folsom, A.R.; Nambi, V.; Bell, E.J.; Oluleye, O.W.; Gottesman, R.F.; Lutsey, P.L.; Huxley, R.R.; Ballantyne, C.M. Troponin T, N-Terminal Pro-B-Type Natriuretic Peptide, and Incidence of Stroke: The Atherosclerosis Risk in Communities Study. Stroke 2013, 44, 961-967. [CrossRef] 
56. Cushman, M.; Judd, S.E.; Howard, V.J.; Kissela, B.; Gutiérrez, O.M.; Jenny, N.S.; Ahmed, A.; Thacker, E.L.; Zakai, N.A. N-Terminal Pro-B-type Natriuretic Peptide and Stroke Risk: The Reasons for Geographic and Racial Differences in Stroke Cohort. Stroke 2014, 45, 1646-1650. [CrossRef]

57. Longstreth, W.T.; Kronmal, R.A.; Thompson, J.L.P.; Christenson, R.H.; Levine, S.R.; Gross, R.; Brey, R.L.; Buchsbaum, R.; Elkind, M.S.V.; Tirschwell, D.L.; et al. Amino Terminal Pro-B-Type Natriuretic Peptide, Secondary Stroke Prevention, and Choice of Antithrombotic Therapy. Stroke 2013, 44, 714-719. [CrossRef]

58. Yaghi, S.; Boehme, A.K.; Hazan, R.; Hod, E.A.; Canaan, A.; Andrews, H.; Kamel, H.; Marshall, R.S.; Elkind, M.S.V. Atrial Cardiopathy and Cryptogenic Stroke: A Cross-sectional Pilot Study. J. Stroke Cerebrovasc. Dis. 2016, 25, 110-114. [CrossRef]

59. Rodriguez-Yanez, M.; Arias-Rivas, S.; Santamaria-Cadavid, M.; Sobrino, T.; Castillo, J.; Blanco, M. High pro-BNP levels predict the occurrence of atrial fibrillation after cryptogenic stroke. Neurology 2013,81, 444-447. [CrossRef]

60. Hodgson-Zingman, D.M.; Karst, M.L.; Zingman, L.V.; Heublein, D.M.; Darbar, D.; Herron, K.J.; Ballew, J.D.; de Andrade, M.; Burnett, J.C., Jr.; Olson, T.M. Atrial Natriuretic Peptide Frameshift Mutation in Familial Atrial Fibrillation. N. Engl. J. Med. 2008, 359, 158-165. [CrossRef]

61. Disertori, M.; Quintarelli, S.; Grasso, M.; Pilotto, A.; Narula, N.; Favalli, V.; Canclini, C.; Diegoli, M.; Mazzola, S.; Marini, M.; et al. Autosomal Recessive Atrial Dilated Cardiomyopathy With Standstill Evolution Associated With Mutation of Natriuretic Peptide Precursor A. Circ. Cardiovasc. Genet. 2013, 6, 27-36. [CrossRef] [PubMed]

62. Gudbjartsson, D.F.; Holm, H.; Sulem, P.; Masson, G.; Oddsson, A.; Magnusson, O.T.; Saemundsdottir, J.; Helgadottir, H.T.; Helgason, H.; Johannsdottir, H.; et al. A frameshift deletion in the sarcomere gene MYL4 causes early-onset familial atrial fibrillation. Eur. Heart J. 2017, 38, 27-34. [CrossRef]

63. Nattel, S. Close connections between contraction and rhythm: A new genetic cause of atrial fibrillation/cardiomyopathy and what it can teach us. Eur. Heart J. 2017, 38, 35-37. [CrossRef]

64. Orr, N.; Arnaout, R.; Gula, L.J.; Spears, D.A.; Leong-Sit, P.; Li, Q.; Tarhuni, W.; Reischauer, S.; Chauhan, V.S.; Borkovich, M.; et al. A mutation in the atrial-specific myosin light chain gene (MYL4) causes familial atrial fibrillation. Nat. Commun. 2016, 7, 11303. [CrossRef] [PubMed]

65. Peng, W.; Li, M.; Li, H.; Tang, K.; Zhuang, J.; Zhang, J.; Xiao, J.; Jiang, H.; Li, D.; Yu, Y.; et al. Dysfunction of Myosin Light-Chain 4 (MYL4) Leads to Heritable Atrial Cardiomyopathy with Electrical, Contractile, and Structural Components: Evidence from Genetically-Engineered Rats. JAHA 2017, 6, e007030. [CrossRef]

66. Kamel, H.; Longstreth, W.; Tirschwell, D.L.; Kronmal, R.A.; Broderick, J.P.; Palesch, Y.Y.; Meinzer, C.; Dillon, C.; Ewing, I.; Spilker, J.A.; et al. The AtRial Cardiopathy and Antithrombotic Drugs In prevention After cryptogenic stroke randomized trial: Rationale and methods. Int. J. Stroke 2019, 14, 207-214. [CrossRef]

67. Geisler, T.; Poli, S.; Meisner, C.; Schreieck, J.; Zuern, C.S.; Nägele, T.; Brachmann, J.; Jung, W.; Gahn, G.; Schmid, E.; et al. Apixaban for treatment of embolic stroke of undetermined source (ATTICUS randomized trial): Rationale and study design. Int. J. Stroke 2017, 12, 985-990. [CrossRef]

68. Choi, J.-Y.; Cha, J.; Jung, J.-M.; Seo, W.-K.; Oh, K.; Cho, K.-H.; Yu, S. Left ventricular wall motion abnormalities are associated with stroke recurrence. Neurology 2017, 88, 586-594. [CrossRef]

69. Choi, J.-Y.; Cha, J.; Jung, J.-M.; Seo, W.-K.; Oh, K.; Cho, K.-H.; Yu, S. Left ventricular wall motion abnormality is associated with cryptogenic stroke. Int. J. Stroke 2020, 15, 188-196. [CrossRef] [PubMed]

70. Hosomi, N.; Yoshimoto, T.; Kanaya, Y.; Neshige, S.; Hara, N.; Himeno, T.; Kono, R.; Takeshima, S.; Takamatsu, K.; Ota, T.; et al. Brain Natriuretic Peptide and Particular Left Ventricle Segment Asynergy Associated with Cardioembolic Stroke from Old Myocardial Infarction. J. Stroke Cerebrovasc. Dis. 2016, 25, 1165-1171. [CrossRef]

71. Sunnerhagen, K.S.; Bhargava, V.; Shabetai, R. Regional left ventricular wall motion abnormalities in idiopathic dilated cardiomyopathy. Am. J. Cardiol. 1990, 65, 364-370. [CrossRef]

72. Ishiwata, S.; Nishiyama, S.; Nakanishi, S.; Seki, A. Two types of left ventricular wall motion abnormalities with distinct clinical features in patients with hypertrophic cardiomyopathy. Eur. Heart J. 1993, 14, 1629-1639. [CrossRef] [PubMed]

73. Fernandes, A.R.; Roma-Rodrigues, C. Genetics of hypertrophic cardiomyopathy: Advances and pitfalls in molecular diagnosis and therapy. TACG 2014, 7, 195. [CrossRef]

74. Ingles, J.; Burns, C.; Barratt, A.; Semsarian, C. Application of Genetic Testing in Hypertrophic Cardiomyopathy for Preclinical Disease Detection. Circ. Cardiovasc. Genet. 2015, 8, 852-859. [CrossRef] [PubMed]

75. Maron, B.J.; Maron, M.S.; Semsarian, C. Genetics of Hypertrophic Cardiomyopathy after 20 Years. J. Am. Coll. Cardiol. 2012, 60, 705-715. [CrossRef] [PubMed]

76. Marian, A.J.; Braunwald, E. Hypertrophic Cardiomyopathy: Genetics, Pathogenesis, Clinical Manifestations, Diagnosis, and Therapy. Circ. Res. 2017, 121, 749-770. [CrossRef]

77. Mestroni, L.; Brun, F.; Spezzacatene, A.; Sinagra, G.; Taylor, M.R.G. Genetic causes of dilated cardiomyopathy. Prog. Pediatric Cardiol. 2014, 37, 13-18. [CrossRef] [PubMed]

78. Rosenbaum, A.N.; Agre, K.E.; Pereira, N.L. Genetics of dilated cardiomyopathy: Practical implications for heart failure management. Nat. Rev. Cardiol. 2020, 17, 286-297. [CrossRef]

79. Dellefave, L.; McNally, E.M. The genetics of dilated cardiomyopathy. Curr. Opin. Cardiol. 2010, 25, 198-204. [CrossRef]

80. Kim, Y.; Kim, T.J.; Lee, S.-H. Cardiac wall motion abnormality as a predictor for undetermined stroke with embolic lesion-pattern. Clin. Neurol. Neurosurg. 2020, 191, 105677. [CrossRef] 